\title{
Pathway-Selective Adjustment of Prefrontal-Amygdala Transmission during Fear Encoding
}

\author{
Maithe Arruda-Carvalho and Roger L. Clem \\ The Fishberg Department of Neuroscience and the Friedman Brain Institute, Icahn School of Medicine at Mount Sinai, New York, New York 10029
}

Conditioned fear requires neural activity in the basolateral amygdala (BLA) and medial prefrontal cortex (mPFC), structures that are densely interconnected at the synaptic level. Previous work has suggested that anatomical subdivisions of mPFC make distinct contributions to fear expression and inhibition, and that the functional output of this processing is relayed to the BLA complex. However, it remains unknown whether synaptic plasticity in mPFC-BLA networks contributes to fear memory encoding. Here we use optogenetics and ex vivo electrophysiology to reveal the impact of fear conditioning on BLA excitatory and feedforward inhibitory circuits formed by projections from infralimbic (IL) and prelimbic (PL) cortices. In naive mice, these pathways recruit equivalent excitation and feedforward inhibition in BLA principal neurons. However, fear learning leads to a selective decrease in inhibition:excitation balance in PL circuits that is attributable to a postsynaptic increase in AMPA receptor function. These data suggest a pathway-specific mechanism for fear memory encoding by adjustment of mPFC-BLA transmission. Upon reengagement of PL by conditioned cues, these modifications may serve to amplify emotional responses.

Key words: amygdala; channelrhodopsin; fear; memory; prefrontal; synaptic plasticity

\section{Introduction}

The basal and lateral nuclei of the amygdala (together the BLA) have been established as crucial loci in fear memory acquisition and retrieval, functions supported in part by synaptic input from thalamic and neocortical sensory regions (Pape and Pare, 2010). In addition to sensory relays, BLA is thought to rely on bidirectional synaptic connections with an emotional regulatory network comprised of the hippocampus and the mPFC. While fear acquisition can occur in the absence of mPFC function (Corcoran and Quirk, 2007), evidence suggests that fear expression is highly contingent on neural processing by $\mathrm{MPFC}$ areas including rostral anterior cingulate $(\mathrm{Cg} 1)$, prelimbic $(\mathrm{PL})$ and infralimbic (IL) cortices (or their human counterparts the dorsal anterior cingulate, dACC, and ventromedial PFC; Phelps et al., 2004; Milad et al., 2007). In particular, conditioned stimulus (CS) responses in PL correlate with the onset and offset of conditioned freezing in rodents (Burgos-Robles et al., 2009; Courtin et al., 2014), and inactivation of PL abolishes fear expression (Corcoran and Quirk, 2007; Sierra-Mercado et al., 2011). In contrast, IL activity is associated with fear inhibition (Milad and Quirk,

\footnotetext{
Received June 30, 2014; revised Sept. 16, 2014; accepted 0ct. 9, 2014.

Author contributions: M.A.-C. and R.L.C. designed research; M.A.-C. performed research; M.A.-C. and R.L.C. analyzed data; M.A.-C. and R.L.C. wrote the paper.

This work was supported by a National Alliance for Research on Schizophrenia and Depression Young Investigator Grant from the Brain and Behavioral Research Foundation (to R.L.C.), generous seed funds from the Icahn School of Medicine (to R.L.C.), and a postdoctoral fellowship from the Human Frontiers Foundation (to M.A.-C.).

The authors declare no competing financial interests.

Correspondence should be addressed to Roger L. Clem, Fishberg Department of Neuroscience, Friedman Brain Institute, Icahn School of Medicine at Mount Sinai, 1470 Madison Avenue, Box 1065, New York, NY 10029. E-mail: roger.clem@mssm.edu.

DOI:10.1523/JNEUROSCI.2664-14.2014

Copyright $\odot 2014$ the authors $\quad 0270-6474 / 14 / 3415601-09 \$ 15.00 / 0$
}

2002). Importantly, CS-responsive neurons in PL project to the amygdala, but not the periaqueductal gray (Courtin et al., 2014), suggesting that synaptic integration of mPFC-BLA inputs is likely critical to the outcome of CS exposure. This possibility is supported by increased firing of BLA neurons during $\mathrm{MPFC}$ microstimulation (Likhtik et al., 2005; but see Rosenkranz and Grace, 2001). However, whether fear conditioning alters the efficacy of transmission at specific mPFC inputs remains to be examined.

Increasingly sophisticated approaches have recently culminated in fairly definitive support for the causal role of synaptic plasticity in associative fear (Nabavi et al., 2014). A next step in linking these insights to the function of fear regulatory pathways would be to localize synaptic correlates of fear conditioning to specific circuits. Despite being essential components of a dysregulated network in fear-related disorders (Maren et al., 2013), however, mPFC-BLA connections have eluded such analysis primarily due to the lack of appropriate methodology. Here we employ a precise optogenetic approach for selective interrogation of BLA circuits formed by projections from the IL and PL subdivisions of mPFC. We demonstrate that despite exhibiting similar basal excitatory and feedforward inhibitory transmission, these pathways are differentially affected by auditory fear conditioning. Our results suggest a novel role for strengthening of PL synapses in fear memory encoding through a postsynaptic mechanism involving AMPA-type glutamate receptors.

\section{Materials and Methods}

Subjects. All subjects were male C57BL/6J mice aged $\sim 4$ postnatal weeks at the time of surgical manipulations and $\sim 10$ weeks at the time of behavioral manipulations. Subjects were housed in groups of three to five on a $12 \mathrm{~h}$ light/dark cycle and given food and water ad libitum. All manipulations were approved in advance by the Institutional Animal 
Care and Use Committee of the Icahn School of Medicine at Mount Sinai.

Viral targeting. Subjects were anesthetized with a mixture of ketamine and xylazine, and mounted in a stereotaxic frame (Stoelting). A small volume of $\mathrm{AAV}_{2}$-CaMKII $\alpha$-ChR2(H134R)-EYFP ( $0.5 \mu$ l; University of North Carolina Vector Core) was injected into each target hemisphere by way of a motorized microsyringe. After remaining in place for 10 additional minutes, the syringe was retracted and mice were recovered to their home cages for 6 weeks until further manipulation. To empirically establish stereotaxic coordinates for PL (AP + 1.9, ML $\pm 0.3, \mathrm{DV}-2.2$ ) and IL (AP +1.7, ML $\pm 0.3, \mathrm{DV}-2.7)$, and analyze their pattern of axonal targeting, animals were transcardially perfused with PBS $(0.1 \mathrm{M})$ and $4 \%$ PFA. Coronal sections $(50 \mu \mathrm{m})$ were obtained from fixed brains on a vibratome (VT1000S; Leica) and mounted using Prolong gold antifade mounting medium with DAPI (Invitrogen). EYFP was visualized using epifluorescent (Axiophot; Zeiss) or confocal (LSM 780; Zeiss) microscopes. For all mice included in this study, we retained the prefrontal brain region for post hoc confirmation of targeting. Following collection and analysis of electrophysiological data, this tissue was fixed overnight with $4 \%$ PFA and processed as previously described. Blind to experimental group, mice containing unintended viral spread into PL or IL were rejected based on confocal fluorescence microscopy. Of 101 total mice, this resulted in elimination of data from 14 .

Fear conditioning. Training entailed six pairings of tone (CS, $2 \mathrm{kHz}, 80$ dB., $20 \mathrm{~s}$ ) with scrambled footshock [unconditioned stimulus (US), 0.7 $\mathrm{mA}, 2 \mathrm{~s}$ ], in which CS and US were coterminating. A $200 \mathrm{~s}$ period of acclimation to the conditioning arena (Med Associates) preceded the onset of the first pairing. After training, mice were returned to their home cages for $24 \mathrm{~h}$ until preparation of brain slices. Several altered conditions were used to test the stimulus specificity of tone conditioning as well as associated synaptic changes. For the tone-only condition, mice experienced 6 CS, but no US, in the training arena. For the immediate shock condition (IMS), mice experienced a single US immediately after placement into the training arena and $60 \mathrm{~s}$ later were returned to their home cages (Frankland et al., 2004). In the unpaired condition, mice experienced the same number of CS and US as trained mice, but in an explicitly unpaired configuration entailing a group of 6 CS followed by a group of 6 US (Clem and Huganir, 2010). Tone-evoked retrieval was conducted $24 \mathrm{~h}$ after training by presentation of a single CS ( $60 \mathrm{~s}$ duration) after a 4 min baseline period in a modified context. Two hours after the tone test, contextual fear was assessed by exposure to the training context for 5 min. Freezing during fear conditioning and tone-evoked retrieval were quantified by automated motion-sensitive software (Video Freeze; Med Associates).

Slice electrophysiology. After anesthetization with isoflurane, subjects received transcardial perfusion with ice-cold $\left(0-4^{\circ} \mathrm{C}\right)$ buffer composed of the following (in mM): 210.3 sucrose, 11 glucose, $2.5 \mathrm{KCl}, 1 \mathrm{NaH}_{2} \mathrm{PO}_{4}$, $26.2 \mathrm{NaHCO}_{3}, 0.5$ ascorbate, $0.5 \mathrm{CaCl}_{2}$, and $4 \mathrm{MgCl}_{2}$. Acute coronal slices of BLA were obtained from dissected brains at $350 \mu \mathrm{m}$ from a VT1200S vibratome (Leica) and then incubated at $35^{\circ} \mathrm{C}$ for $40 \mathrm{~min}$ in the same solution, but with reduced sucrose $(105.2 \mathrm{~mm})$ and addition of $\mathrm{NaCl}(109.5 \mathrm{~mm})$. Following recovery, slices were maintained at room temperature in standard ACSF composed of the following (in mM): 119 $\mathrm{NaCl}, 2.5 \mathrm{KCl}, 1 \mathrm{NaH}_{2} \mathrm{PO}_{4}, 26.2 \mathrm{NaHCO}_{3}, 11$ glucose, $2 \mathrm{CaCl}_{2}$, and 2 $\mathrm{MgCl}_{2}$. Whole-cell voltage-clamp recordings were obtained from principal pyramidal neurons in the lateral and basal amygdala using borosilicate glass electrodes (3-5 M $\Omega$ ). Electrode internal was composed of the following (in mM): 120 Cs-methanesulfonate, 10 HEPES, 0.5 EGTA, 8 $\mathrm{NaCl}, 4 \mathrm{Mg}$-ATP, 1 QX-314, 10 Na-phosphocreatine, and 0.4 Na-GTP. $\mathrm{mPFC}$ axon terminals were stimulated using TTL-pulsed microscope objective-coupled LEDs ( $460 \mathrm{~nm}, \sim 1 \mathrm{~mW} / \mathrm{mm}^{2}$; Prizmatix). In experiments requiring $\mathrm{GABA}_{\mathrm{A}} \mathrm{R}$ blockade by picrotoxin $(100 \mu \mathrm{M} ; \mathrm{Abcam})$, external $\mathrm{Ca}^{2+}$ and $\mathrm{Mg}^{2+}$ were increased to $4 \mathrm{~mm}$ to prevent spontaneous bursting. For analysis of AMPA:NMDA ratio and EPSC rectification during LED stimulation, we applied $1 \mu \mathrm{M}$ TTX (Abcam) and $100 \mu \mathrm{M} 4$-AP (Abcam) for more stringent isolation of monosynaptic transmission as previously described (Cruikshank et al., 2010). Paired pulse-evoked EPSC and spontaneous EPSC/IPSC analyses were conducted in normal ACSF. For use-dependent blockade of NMDA receptors, a baseline
NMDAR-EPSC was established at $+40 \mathrm{mV}$ by stimulation in normal ACSF supplemented with AMPA (DNQX, $20 \mu \mathrm{M}$ ) and GABA receptor antagonists (picrotoxin, $100 \mu \mathrm{M})$. MK-801 $(20 \mu \mathrm{M})$ was then applied and $0.1 \mathrm{~Hz}$ stimulation was resumed to trigger progressive and release probability-dependent blockade of NMDAR-EPSCs (Rosenmund et al., 1993). Data were low-pass filtered at $3 \mathrm{kHz}$ (evoked) and $10 \mathrm{kHz}$ (spontaneous) and acquired at $10 \mathrm{kHz}$ using Multiclamp 700B and pClamp 10 (Molecular Devices). All stimulation was conducted at $0.1 \mathrm{~Hz}$ to avoid inducing synaptic plasticity. Series and membrane resistance were continuously monitored, and recordings were discarded when these measurements changed by $>20 \%$. Detection and analysis of sEPSCs and sIPSCs were performed blind to experimental group using Mini Analysis (Synaptosoft).

Statistics. All data are presented as means \pm SE, with $n$ given as number of cells followed by number of animals in parentheses, where applicable. Two-tailed $t$ tests were used for comparisons across two groups, while $>2$ groups were analyzed by one-way or two-way ANOVA followed by pairwise comparisons using Bonferroni-corrected two-tailed $t$ tests.

\section{Results}

To investigate BLA synapses formed by projections from the $\mathrm{mPFC}$, we selectively targeted IL (Fig. 1B) or PL cortices (Fig. 1C) through precise stereotaxic infusion of recombinant adeno-associated viral vectors expressing a channelrhodopsin-2 (ChR2)-EYFP fusion protein under the control of a CaMKII $\alpha$ promoter (rAAV2CaMKII $\alpha$-ChR2(H134R)-EYFP; Fig. 1A). Six weeks after virus infusion, whole-cell recordings were obtained from amygdala neurons during optic excitation of $\mathrm{mPFC}$ terminals by microscope objective-coupled light-emitting diodes (Fig. 2A; LEDs, $460 \mathrm{~nm}, \sim 1 \mathrm{~mW} / \mathrm{mm}^{2}$ ). ChR2-EYFP fluorescence was mostly restricted to $\mathrm{mPFC}$ target structures (Fig. $1 \mathrm{~B}, \mathrm{C}$ ). Generally consistent with previous tracing studies (Sesack et al., 1989; Mcdonald et al., 1996), axon terminal fluorescence was most prominent in the anterior basal nucleus, and displayed a similar pattern following IL and PL infusions (Fig. 1D-G). In accordance with more prominent terminal labeling by ChR2-EYFP in the basal nucleus, LED stimulation evoked larger biphasic EPSC-IPSCs in neurons from basal compared with those in the lateral nucleus (Fig. $1 H$ ), which were exceedingly small even under maximal stimulation (EPSC component $=-20.7 \pm 4.8 \mathrm{pA}$ ). We therefore restricted the remainder of our analysis to the basal amygdala subregion.

To investigate basal nucleus plasticity after fear encoding, we first compared global synaptic properties of principal glutamatergic neurons between slices from naive mice and those subjected to auditory fear conditioning (Fig. $2 A$ ). Examination of a subset of trained mice ( $n=10$ of 38 ) revealed robust tone-evoked freezing at the time point when acute brain slices were prepared (24 $\mathrm{h}$ post training, $t_{(9)}=8.72, p<0.0001$; Fig. $2 C$ ). Compared with naive controls, neurons from trained mice exhibited increased frequency of sEPSCs $\left(t_{(24)}=2.27, p=0.032\right.$; Fig. $\left.2 E\right)$, but no change in sEPSC amplitude $\left(t_{(24)}=1.32, p=0.20\right.$; Fig. $\left.2 F\right)$ or kinetics (rise $t_{(24)}=1.10, p=0.28$; tau decay $\left.t_{(24)}=0.21, p=0.84\right)$. In contrast, no differences in the frequency $\left(t_{(18)}=0.40, p=0.70\right)$, amplitude $t_{(18)}=0.84, p=0.41$ ), or kinetics (rise $t_{(18)}=0.22, p=0.82$; tau decay $\left.t_{(18)}=0.88, p=0.39\right)$ of sIPSCs were detected in trained mice (Fig. $2 G-I)$.

Given a potential shift toward greater excitation in spontaneous transmission after fear conditioning (Fig. 2), we next assessed changes in $\mathrm{mPFC}$ pathways that might affect inhibition:excitation balance of a hypothetical microcircuit (Fig. 3A). A brief light pulse (460 nm, $5 \mathrm{~ms}$ ) evoked an EPSC followed by an IPSC in principal excitatory neurons. After fear conditioning, the amplitude ratio of component IPSCs and EPSCs (I:E ratio) was decreased during PL $\left(t_{(21)}=3.46, p=0.0024\right)$ but not IL terminal 

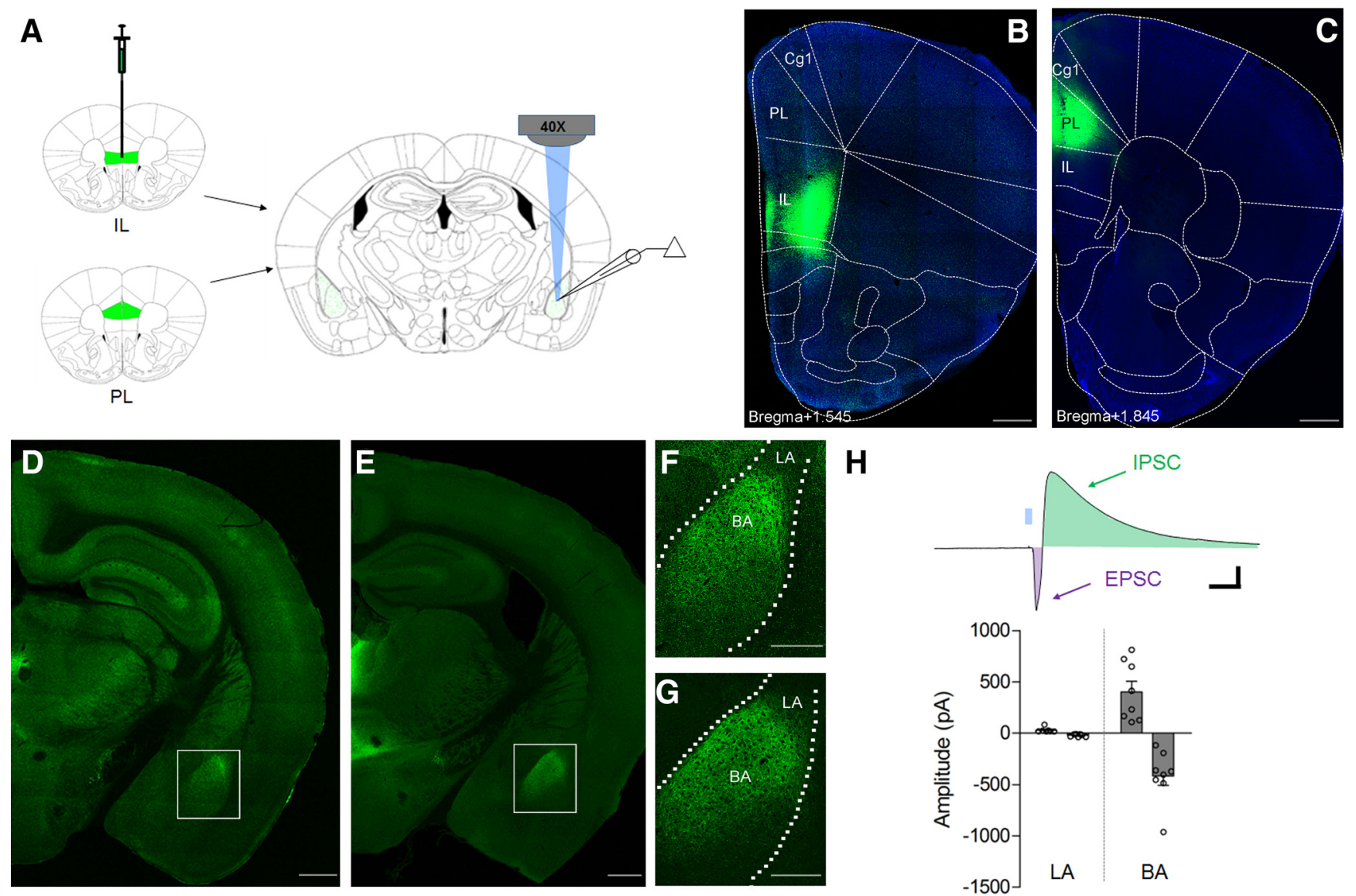

Figure 1. Glutamatergic projections from $\mathrm{mPFC}$ recruit excitatory and inhibitory transmission predominantly in the basal amygdala. $A$, Stereotaxic injections of $\mathrm{AAV}_{2}$-CaMKIl $\alpha$-ChR2(H134R)EYFP were targeted to the IL or PL subregions of $\mathrm{mPFC} 6$ weeks before histology or terminal-specific optogenetic electrophysiology in the BLA. $B$, $C$, Representative examples of EYFP immunofluorescence in IL $(\boldsymbol{B})$ or PL targets $(\boldsymbol{C})$ with DAPI overlay. $\boldsymbol{D}-\mathbf{G}$, Confocal images of terminal-associated EYFP fluorescence in midline thalamic nuclei and BLA after IL $(\boldsymbol{D}, \boldsymbol{F})$ or PL injection $(\boldsymbol{E}, \boldsymbol{G})$. Insets depict enrichment of terminals in the basal (BA), but not the lateral (LA) nucleus of the amygdala $(\boldsymbol{F}, \boldsymbol{G})$. Scale bars: $\boldsymbol{D}, \boldsymbol{E}, 500 \mu \mathrm{m} ; \boldsymbol{F}, \boldsymbol{G}, 250 \mu \mathrm{m} . \boldsymbol{H}, 0$ ptic stimulation of PL terminals (5 ms, $460 \mathrm{~nm})$ evoked large-amplitude biphasic excitatory-inhibitory synaptic responses in principal neurons of the basal, but not the lateral nucleus. Calibration: $60 \mathrm{pA} \times 40 \mathrm{~ms}$.

stimulation $\left(t_{(15)}=0.86, p=0.40\right.$; Fig. $\left.3 B, C\right)$. This shift at the PL pathway was evident over the entire range of maximal response amplitudes for individual neurons (Fig. 3D), suggesting that changes in I:E balance could not be attributed to a bias in response strength.

To more closely examine EPSCs and IPSCs, we relied on the following properties to sequentially isolate these components in individual neurons: the reversal potential of EPSCs $(0 \mathrm{mV})$ and

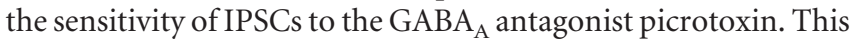
technique allows for the dissociation of currents with onset latencies consistent with monosynaptic excitation and disynaptic inhibition (Fig. $4 A, D$ ). Importantly, we confirmed that IPSCs are generated through a multisynaptic mechanism by application of an AMPA/kainate receptor antagonist (Fig. 4B), consistent with recruitment of local interneurons by $\mathrm{mPFC}$ terminals. While onset latency of response components was unaffected by experience (Fig. 4D), the IPSC:EPSC amplitude ratio was decreased in the PL $\left(t_{(13)}=2.85, p=0.027\right)$ but not IL pathway after training $\left(t_{(14)}=\right.$ $0.0076, p=0.99$; Fig. $4 E$ ). IPSCs exhibited no change in amplitude in either pathway (one-way ANOVA, $F_{(3,29)}=0.66, p=$ 0.58; Fig. $4 F$ ). In contrast, EPSCs in trained mice were increased in amplitude selectively at PL synapses (one-way ANOVA, $F_{(3,28)}=$ 4.12, $p=0.015, p<0.05$ Bonferroni post hoc comparison of $\mathrm{PL}$ trained vs PL naive or IL trained; Fig. $4 F$ ).

The presence of excitatory synaptic strengthening suggests that pathway-selective plasticity of mPFC-BLA transmission contributes to fear memory encoding. However, it remains unclear whether synaptic changes were driven by associative aspects of training, rather than mere exposure to a novel context and/or stimuli. Therefore, we collected additional synaptic physiology from a new group of PL-targeted mice after cage experience (naive), auditory training, or one of three additional control conditions: tone only, immediate shock (IMS), or unpaired conditioning (Fig. 5A). Probe tests indicated that only trained mice displayed increased freezing in the presence of the CS, relative to baseline (Fig. 5B; two-way repeated-measures ANOVA, group $\times$ test interaction, $F_{(3,28)}=16.68, p<0.0001 ; p<0.01$ paired $t$ test for simple effect of test), indicating that tone-associative learning was specific to this condition. In contrast, both unpaired and trained mice, but not IMS mice, exhibited context-evoked freezing during re-exposure to the training arena (Fig. $5 C$; one-way ANOVA, $F_{(3,28)}=15.69, p<0.0001 ; p<0.05$ Bonferroni post hoc comparison of trained or unpaired vs remaining conditions). Optic stimulation of PL terminals revealed that while feedforward IPSC amplitude was not affected by any behavioral condition (Fig. $5 D, E ; F_{(4,46)}=0.26, p=0.90$ ), monosynaptic EPSCs were strengthened in trained mice relative to all other control conditions (Fig. 5F, $G$; $F_{(4,45)}=7.31, p=0.0001, p<0.05$ Bonferroni post hoc comparison of trained vs all other conditions). Further indicating the requirement for stimulus associativity in PL-BLA plasticity, within-cell IPSC:EPSC ratios were decreased in trained mice relative to unpaired controls [IPSC:EPSC ratio: 
A

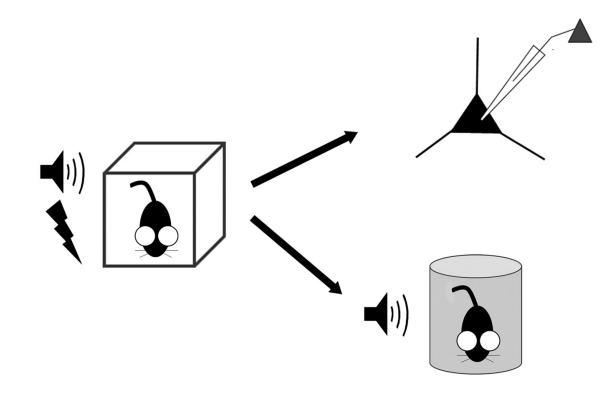

D

naive

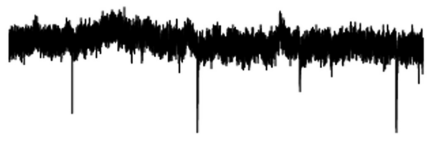

trained

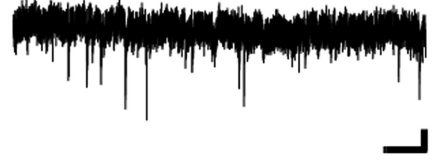

G

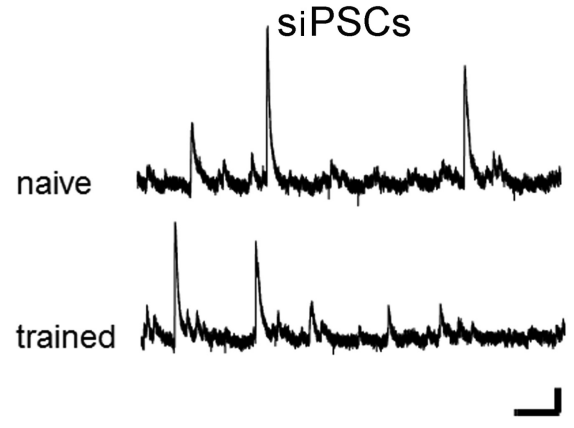

B

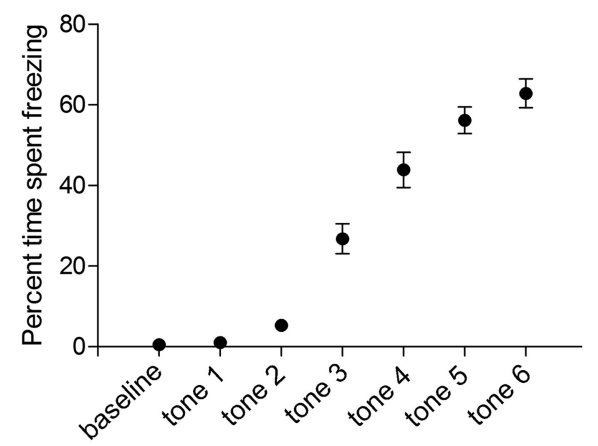

E

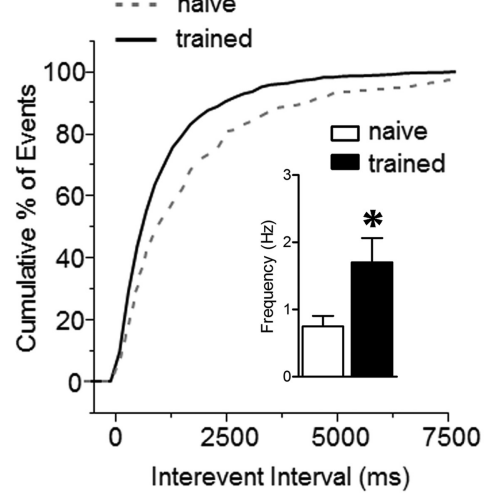

H

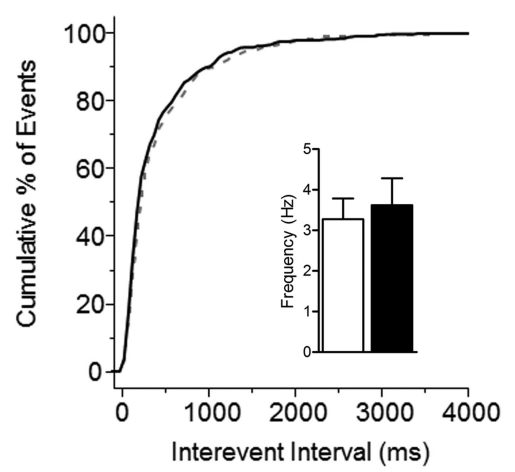

C

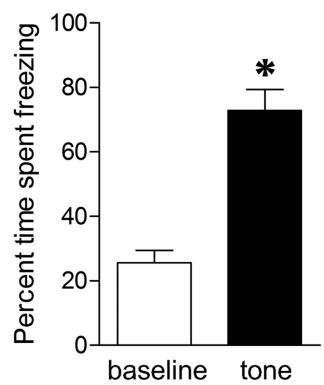

I

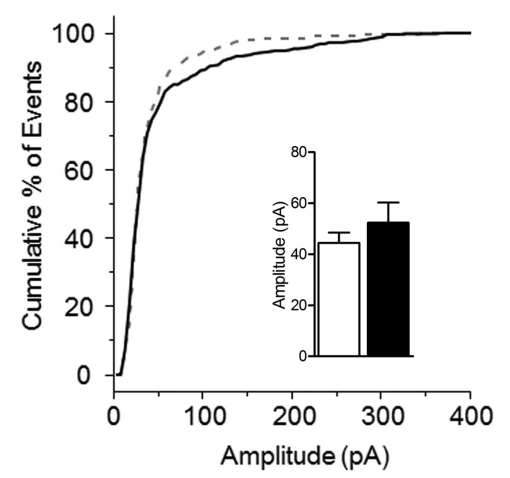

Figure 2. Limited impact of fear conditioning on spontaneous neurotransmission in the basal nucleus. $A$, Schedule for obtaining electrophysiological or behavioral measurements for all trained mice. Training entailed six pairings of pure-tone $C S(2 \mathrm{kHz}, 20 \mathrm{~s}, 80 \mathrm{~dB})$ with scrambled footshock US $(0.7 \mathrm{~mA}, 2 \mathrm{~s})$, while naive mice were selected from cage-experienced littermates. $B, C$, Freezing during fear conditioning $(\boldsymbol{B})$ and retrieval test $(\boldsymbol{C}) .{ }^{*} p<0.0001$, paired $t$ test versus baseline $(n=10)$. $\boldsymbol{D}$, Representative $\mathrm{EEPSC}$ traces at $-60 \mathrm{mV}$. Calibration: $10 \mathrm{pA} \times 400 \mathrm{~ms}$. $\boldsymbol{E}, \boldsymbol{F}$, Cumulative distribution and group means for frequency $(\boldsymbol{E})$ and amplitude $(\boldsymbol{F})$ of $\mathrm{sEPSCS},{ }^{*} p<0.05$, two-tailed $t$ test $[n=12(5)$ naive, 14 (4) trained]. G, Representative sIPSC traces at $0 \mathrm{mV}$. Calibration: 30 $\mathrm{pA} \times 300 \mathrm{~ms}$. $\boldsymbol{H}, \boldsymbol{I}$, Cumulative distribution and group means for frequency $(\boldsymbol{H})$ and amplitude $(\boldsymbol{I})$ of $\operatorname{sIPSCs}[n=9(3)$ naive, 11 (3) trained].

unpaired $=1.94 \pm 0.24 ;$ trained $=1.08 \pm 0.22 ; t_{(11)}=2.55, p=$ 0.027; $n=5$ (5) unpaired, 8 (4) trained].

Due to enhancement of sEPSC frequency in basal amygdala neurons after fear conditioning (Fig. 2), we hypothesized that potentiation of PL excitatory responses might have a presynaptic locus of expression. Indeed, fear conditioning has been previously associated with increased miniature EPSC frequency in lateral amygdala neurons (Clem and Huganir, 2010), as well as increased glutamate release at cortical synapses formed by external capsule inputs (Tsvetkov et al., 2002). Importantly, a lack of ChR2-EYFP fluorescence in the external capsule indicates that although they originate from neocortex, PL fibers likely enter the basal amygdala through an alternate pathway (Fig. 1), similar to anterior cingulate fibers targeting the lateral amygdala (Morozov et al., 2011). To assess glutamate release probability at PL synapses, we delivered paired-pulse LED stimulation over a range of interstimulus intervals (Fig. $6 A, B$ ). This revealed that fear conditioning does not alter paired-pulse EPSC ratios under our recording conditions (100 ms interstimulus interval; $t_{(18)}=0.10 ; p=0.92$; Fig. $6 B$ ). To provide an independent test of presynaptic function, we took advantage of the use dependence of the NMDA receptor antagonist MK801 (Rosenmund et al., 1993), which results in an increased rate of EPSC blockade with higher glutamate release probability. During stimulation in MK-801 $(20 \mu \mathrm{M})$, the time constant of NMDAREPSC blockade did not differ between naive and trained mice (Fig. $\left.6 C-E ; t_{(13)}=0.097, p=0.92\right)$, and thus increased strength of PL excitatory synapses cannot be attributed to presynaptic plasticity.

To examine whether PL response potentiation might arise from postsynaptic modifications, we compared the relative contribution of AMPA and NMDA receptor currents to excitatory 
A

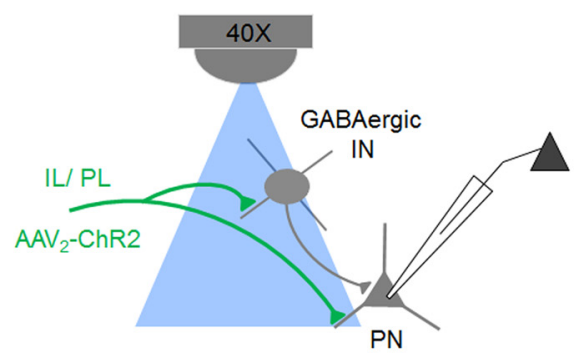

C

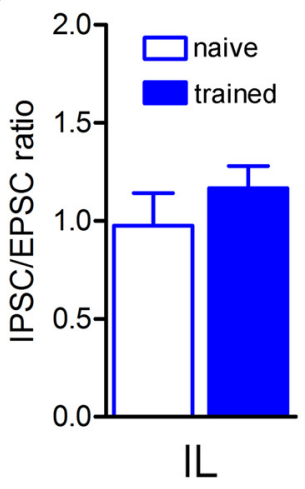

B

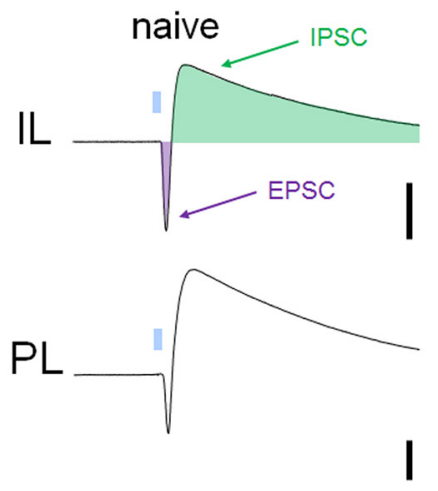

D

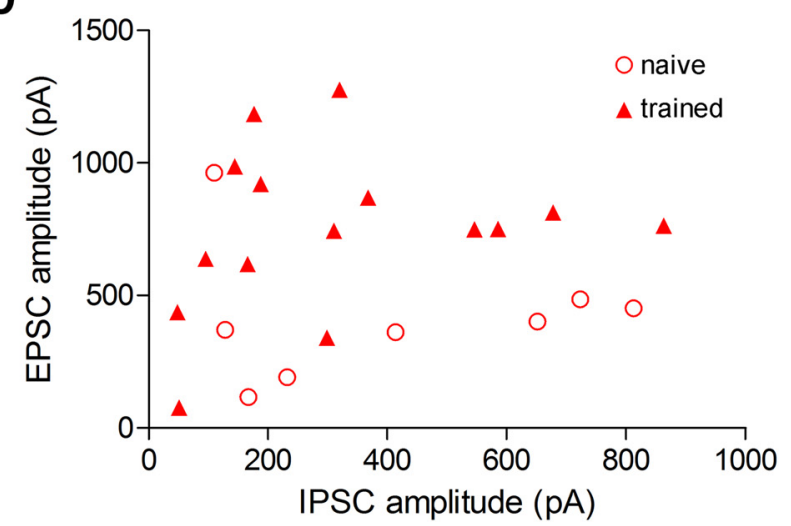

Figure 3. Fear conditioning reduces the balance of inhibition to excitation in the PL-amygdala pathway. $\boldsymbol{A}$, Hypothetical model of glutamatergic excitation and local feedforward inhibition in principal neurons resulting from optic stimulation of IL or PL BLA terminals onto interneurons (IN) or principal neurons (PN). B, Representative biphasic EPSC-IPSCs evoked by optic stimulation (5 ms, $460 \mathrm{~nm}$ ) of IL or PL terminals with postsynaptic neuron clamped at $-50 \mathrm{mV}$. Calibration: $300 \mathrm{pA} \times 40 \mathrm{~ms}$. C, Mean amplitude ratio of I:E ratio as a function of training. $D$, Distribution of component amplitudes for individual neurons during PL stimulation. ${ }^{*} p<0.05$, two-tailed $t$ test [IL $n=10$ (5) naive, 7 (6) trained; PL $n=8(7)$ naive, 15 (9) trained].

transmission during optic stimulation. Since LTP of postsynaptic origin is typically attributable to increased AMPA receptor conductance (Kauer et al., 1988; Muller et al., 1988), previous studies have relied on this metric as an indicator of postsynaptic strengthening (Clem and Barth, 2006; Tye et al., 2008; Clem and Huganir, 2010; Lammel et al., 2011; Britt et al., 2012). Similar to artificial LTP, fear conditioning increased AMPA:NMDA ratios at PL synapses $\left(t_{(20)}=2.48, p=0.022\right.$; Fig. $\left.7 A, B\right)$. In previous work, we found that fear conditioning also leads to strengthening of AMPA receptor transmission at thalamic synapses in the lateral nucleus, and that this strengthening is associated with synaptic incorporation of inwardly rectifying calcium-permeable AMPARs (CP-AMPARs; Clem and Huganir, 2010, 2013). Similar to thalamic synapses, AMPAR-EPSCs at PL synapses displayed greater inward rectification in trained animals $\left(t_{(24)}=2.30, p=\right.$ 0.030; Fig. 7C,D), indicating that fear memory formation leads to a change in AMPAR subunit composition in the PL pathway. Together, these data support a postsynaptic locus for plasticity underlying fear encoding within the mPFC-BLA network.

\section{Discussion}

In these experiments we used optogenetics and ex vivo electrophysiology to reveal plasticity of mPFC-BLA circuits after fear learning. Through precise stereotaxic infusion of ChR2 vectors, we were able to isolate for optic stimulation BLA inputs from either PL or IL cortices and examine the impact of fear conditioning on pathway-specific excitation and inhibition. We found that fear learning leads to strengthening of PL but not IL excitatory synapses in BLA principal neurons via changes in AMPAR con- ductance, without corresponding changes in feedforward inhibition in either pathway. These effects emphasize the power of optogenetics when applied to the precise functional dissection of brain circuits, and reveal a synaptic mechanism mediating mPFC-BLA cooperation in fear memory encoding.

Previous studies of auditory fear conditioning have focused predominantly on the role of synaptic plasticity in the lateral nucleus. For example, strengthening of thalamic synapses formed by internal capsule inputs can be readily detected in acute brain slices from trained animals (McKernan and Shinnick-Gallagher, 1997; Zhou et al., 2009; Clem and Huganir, 2010; Lin et al., 2011; Hong et al., 2013), and these ex vivo effects mirror changes in short-latency auditory field potentials in the lateral nucleus in vivo (Rogan et al., 1997). Interestingly, similar effects have been reported following auditory-cued reward learning and are predictive of behavioral performance (Tye et al., 2008). While these data suggest a causal relationship between thalamic synaptic efficacy and emotional learning, a recent study that used optogenetic manipulation of thalamic synapses suggested this model is inadequate (Nabavi et al., 2014). According to this report, once fear memory has been established, low-frequency optogenetic stimulation both weakens thalamic synapses and reduces fear, while high-frequency stimulation can reverse this weakening and restore CS responses. Nevertheless, LTP-like strengthening of thalamic synapses is not sufficient to generate fear in naive animals. Thus, while plasticity in the thalamic pathway is critical for fear conditioning, other synapses recruited by CS-US pairing are likely necessary for fear memory encoding. These additional sites 
A

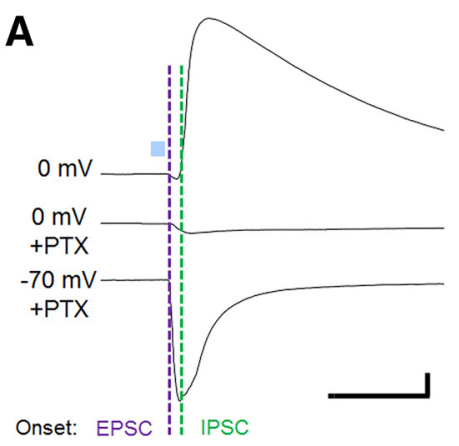

B

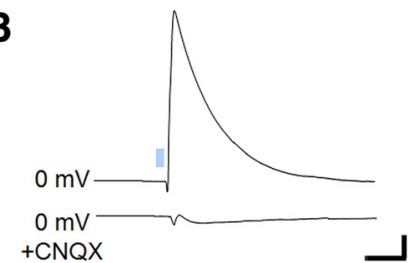

C
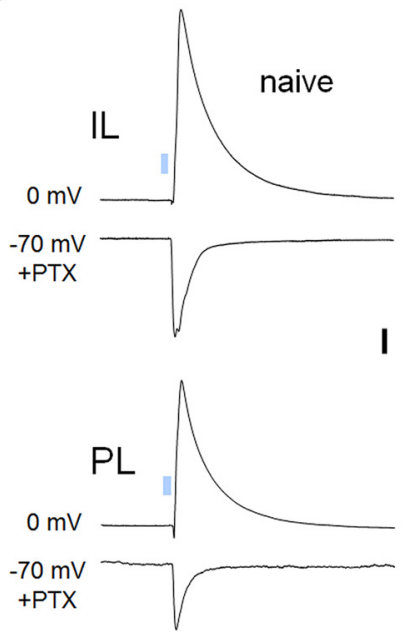

I

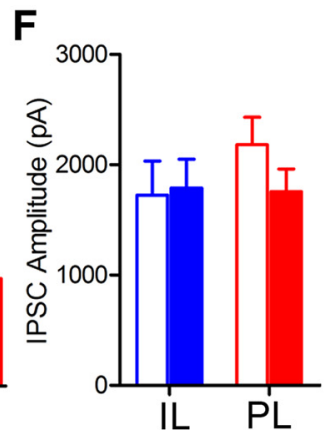

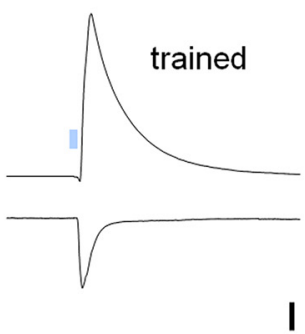
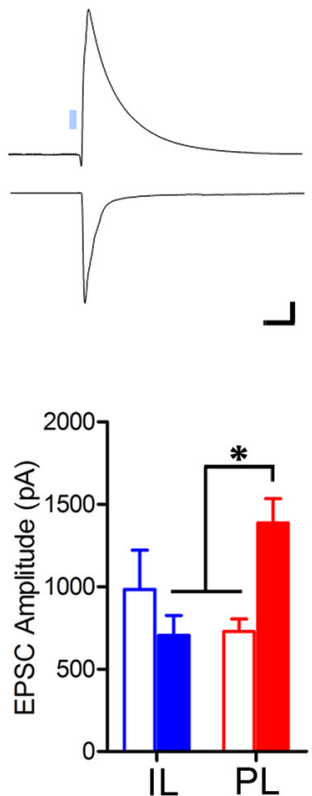

Figure 4. Potentiation of monosynaptic excitation underlies plasticity of PL circuits. $A$, Pharmacological isolation of excitatory response component by $G A B A_{A}$ receptor blockade (100 $\mu \mathrm{M}$ picrotoxin). Calibration: $300 \mathrm{pA} \times 50 \mathrm{~ms}$. B, Confirmation of polysynaptic IPSC mechanism by application of the AMPA receptor antagonist CNQX (100 $\mu$ M) during PL optic stimulation. Calibration: $400 \mathrm{pA} \times 70 \mathrm{~ms}$. C, Representative IPSCs and pharmacologically isolated EPSCs for single neurons during IL and PL stimulation. Calibration: $200 \mathrm{pA} \times 50 \mathrm{~ms}$. D, Onset latency of EPSCs and putative disynaptic IPSCS for all groups. $\boldsymbol{E}$, Reduction of IPSC:EPSC ratio in the PL pathway. ${ }^{*} p<0.05$, two-tailed $t$ test. [For IL $n=8(6)$ naive, $8(6)$ trained; PL $n=8(7)$ naive, 7 (7) trained.] $\boldsymbol{F}$, Selective potentiation of EPSC amplitude [IL $n=8(6)$ naive, 7 (6) trained; PL $n=8(7)$ naive, $9(8)$ trained] in the PL pathway after fear conditioning, but no effect of training on IPSC amplitudes [IL $n=9$ (6) naive, 8 (6) trained; $\mathrm{PL} n=8(7)$ naive, 8 (7) trained]. ${ }^{*} p<0.05$, Bonferroni post hoc comparison.

need to be identified to enable systems-level dissection and reconstruction of emotional memory processes.

An appropriate focus for these experiments is the mPFC-BLA network, given its complex roles in both fear expression and extinction. This network is characterized by extensive and reciprocal axon projections from principal glutamatergic neurons (Marek et al., 2013). Ambiguity exists regarding the functional impact of these projections, particularly with respect to their relative engagement of downstream excitatory and inhibitory neurons. For example, it has been presumed that IL neurons predominantly recruit inhibitory microcircuits within the BLA (Marek et al., 2013), thereby explaining correlation of IL activity with extinction. As with other recent reports (Cho et al., 2013; Hübner et al., 2014), the application of advanced electrophysiological techniques in our study enabled a direct comparison of the nature and relative strength of transmission between PL and IL pathways. The results of these studies are in complete agreement that PL and IL provide largely overlapping axon projections that recruit similar levels of functional excitation and inhibition. $\mathrm{Nev}-$ ertheless, CS-evoked activity in MPFC and BLA, as well as rhythmic coupling between these structures, suggests their close cooperation in fear encoding. Realistic computational models suggest that processing by the mPFC-BLA network may trans- form transient CS-evoked activity in the lateral amygdala into a sustained output via PL projections to the basal nucleus (Pendyam et al., 2013), while in vivo recordings indicate that such projections do indeed originate from CS-responsive neurons (Courtin et al., 2014). Our results indicate that fear responses may be additionally modulated by plasticity of these mPFC-BLA connections.

We demonstrate for the first time that fear encoding involves strengthening of BLA synapses from a specific group of neurons in the mPFC. However, ours is not the first application of optogenetic techniques to experience-dependent plasticity in these pathways. In an initial report that focused on extinction, ChR2 vectors were targeted to IL, but this resulted in considerable spread into PL (Cho et al., 2013). The authors reported no differences in transmission between CS-only and fear-conditioned controls at synapses formed by these mixed projections. However, in fear-extinguished mice, excitatory transmission was weakened through reduction of glutamate release probability. These results essentially agree with those of our study in that the IL-BLA pathway is unaffected by fear conditioning, and indicate that mPFC-BLA plasticity may be important for multiple stages of bidirectional fear regulation. However, although PL and IL have largely overlapping BLA terminal fields, our data indicate 
A

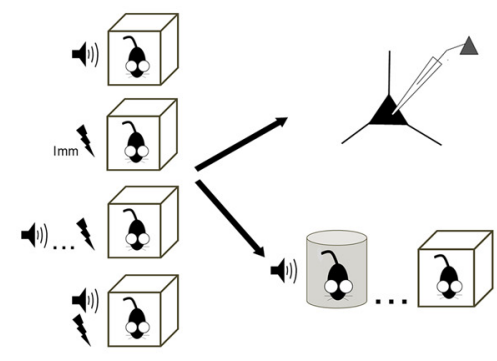

B

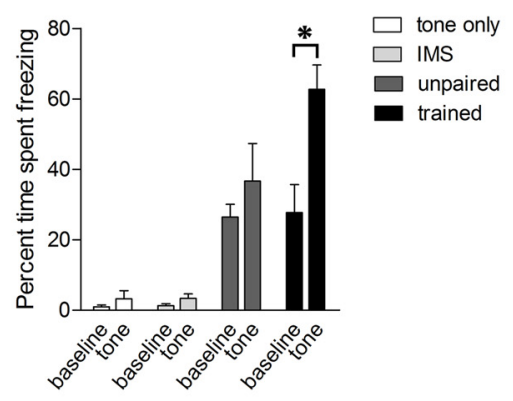

$\mathbf{F}$
C

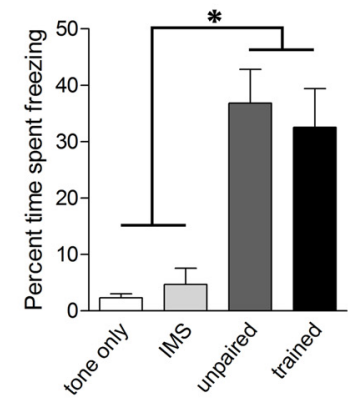

D

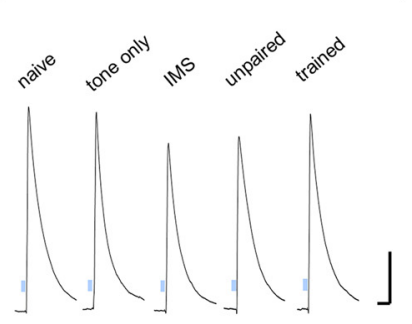

E

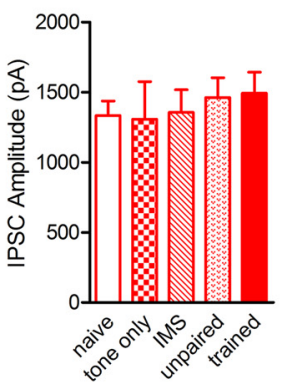

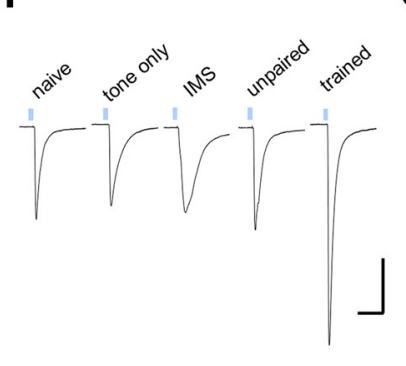

G

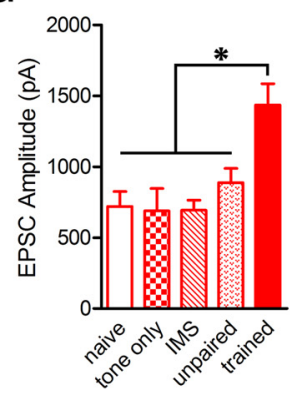

Figure 5. PL excitatory synaptic strengthening requires tone-associative fear learning. $A$, Schedule for obtaining electrophysiological or behavioral measurements after auditory training or control experience. Training entailed six pairings of pure-tone $\mathrm{CS}(2 \mathrm{kHz}, 20 \mathrm{~s}, 80 \mathrm{~dB})$ with scrambled footshock US $(0.7 \mathrm{~mA}, 2 \mathrm{~s})$. Tone-only mice experienced $6 \mathrm{CS}$, but no shocks. Immediate shock (IMS) mice experienced a single shock $(0.7 \mathrm{~mA}, 2 \mathrm{~s})$ immediately after placement into the training arena. Unpaired mice experienced the same number of $\mathrm{CS}$ and US as trained mice, but in an explicitly unpaired configuration. $\boldsymbol{B}, \boldsymbol{C}$, Comparison of baseline and tone-evoked freezing $\left(\boldsymbol{B}_{;}^{*} \boldsymbol{{ } ^ { * }}<<0.01\right)$ and freezing to the training context (average of 5 $\min ;{ }^{*} p<0.05$, Bonferroni post hoc comparison; $\boldsymbol{C}$ ) at $24 \mathrm{~h}$ after training. $n=9$ tone only, $n=8 \mathrm{IMS}, n=7$ unpaired, $n=8$ trained. $\boldsymbol{D}, \boldsymbol{E}$, No effect of training on feedforward IPSC amplitude during PL terminal stimulation $] n=11$ (4) naive, 8 (3) tone only, 9 (5) IMS, 10 (5) unpaired, 13 (5) trained]. Calibration: 400 pA $\times 80$ ms. $\boldsymbol{F}$, Representative EPSCs for PL stimulation. Calibration: $400 \mathrm{pA} \times 80 \mathrm{~ms}$. G, Associative training increases EPSC amplitude relative to all control groups. ${ }^{*} p<0.05$, Bonferroni post hoc comparison [ $n=11$ (4) naive, 7 (3) tone only, 10 (5) IMS, 12 (5) unpaired, 10 (5) trained].

A

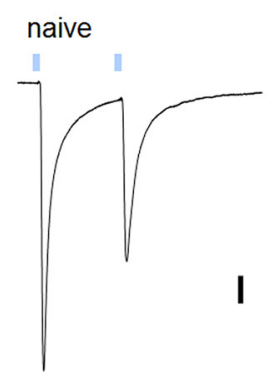

C
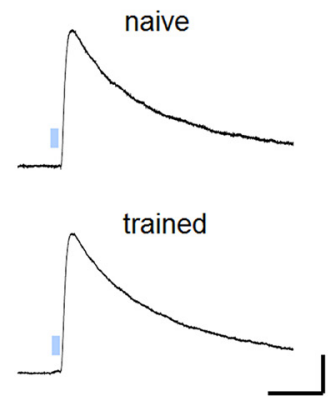

trained

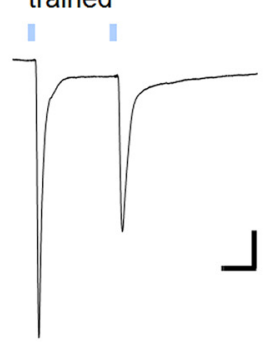

B
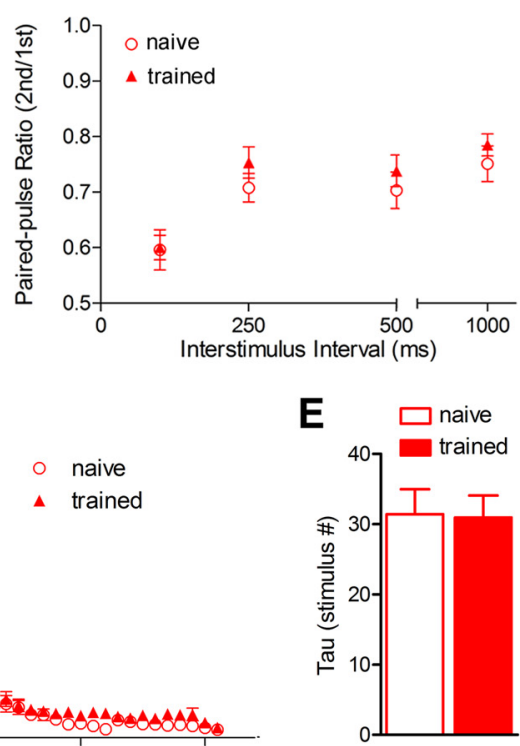

Figure 6. Glutamate release probability of PL synapses is unaltered after fear conditioning. $A$, Representative traces of EPSCs evoked by paired optic stimulation at $100 \mathrm{~ms}$ interpulse interval. Calibration: 100 (left) and $200 \times 40 \mathrm{~ms}$ (right). $\boldsymbol{B}$, Mean amplitude ratios for paired-pulse stimulation [second/first pulse; $(n=10$ (2) naive, 10 (3) trained]. $\boldsymbol{C}-\boldsymbol{E}$, Use-dependent blockade of NMDA receptors by MK-801 (40 $\mu \mathrm{M})$ during $0.1 \mathrm{~Hz}$ optic stimulation. Response amplitudes $(\boldsymbol{D})$ were normalized to the first optic stimulus $(\boldsymbol{C})$ and averaged across bins of five stimuli. Calibration: $100 \mathrm{pA} \times 80 \mathrm{~ms}$. $\boldsymbol{E}$, Comparison of mean time constant for NMDA receptor blockade, derived from a single-exponential fit of [amplitude $\times$ pulse number] for individual cells [ $n=8$ (4) naive, 7 (3) trained]. 
A
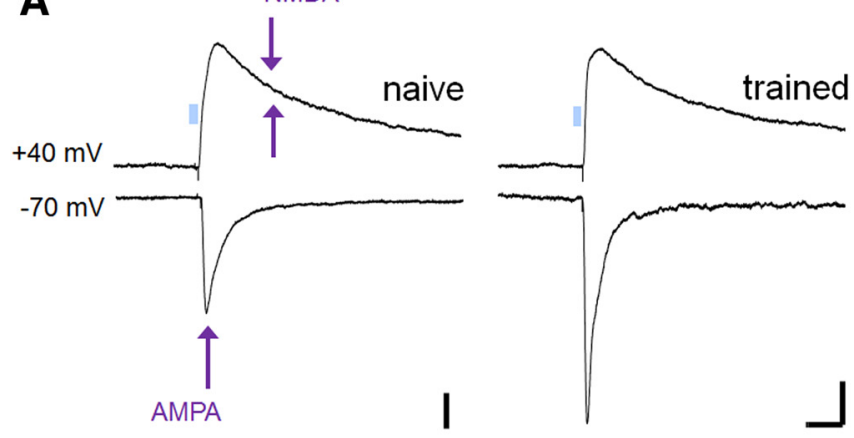

C

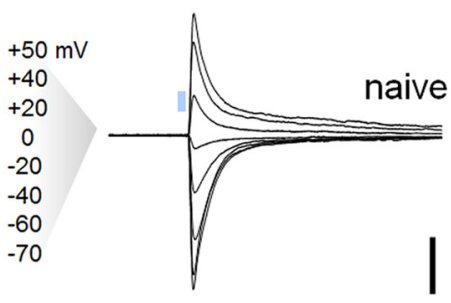

B

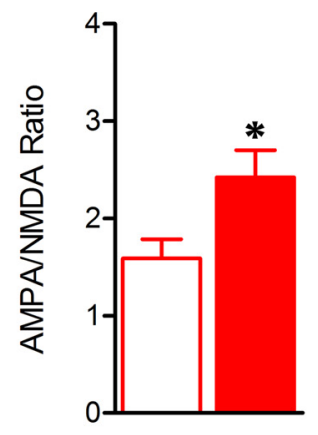

D

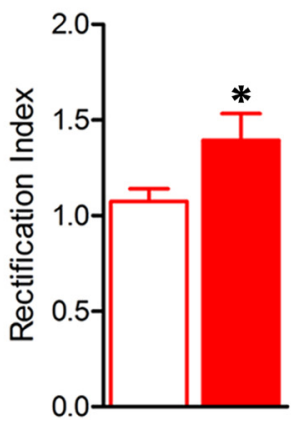

Figure 7. Plasticity of AMPA receptor transmission underlies training-related increase in PL postsynaptic efficacy. A, Representative traces of EPSCs evoked by optic stimulation with the postsynaptic neuron clamped at -70 and $+40 \mathrm{mV}$ to compare AMPA and NMDA receptor components of glutamatergic transmission, respectively. Arrows indicate time of amplitude measurements. Calibration: $100 \mathrm{pA} \times 50 \mathrm{~ms}$. $\boldsymbol{B}$, Mean AMPA:NMDA ratio was increased after fear conditioning ${ }^{*} p<0.05$, two-tailed $t$ test $[n=12$ (4) naive, 10 (5) trained]. $\boldsymbol{C}$, Representative traces of AMPAR-EPSCs at indicated voltages in the presence of an NMDAR antagonist (D,L-APV, $100 \mu \mathrm{M})$ and internal spermine $(100 \mu \mathrm{M})$. $\boldsymbol{D}$, Index of inward rectification for AMPAR-EPSCs was increased after

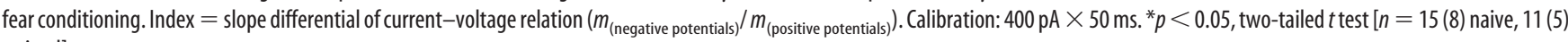
trained].

that these pathways play divergent roles in fear memory processes, which may be obscured by their nonselective targeting. Future studies should attempt to disambiguate these pathways by the use of appropriate AAV serotypes, injection volumes, and target angles. In addition, due to reciprocity of mPFC-BLA connectivity (Little and Carter, 2013; Senn et al., 2014), experiments should also examine whether BLA synapses onto mPFC neurons exhibit fear-related plasticity.

Similar to thalamic plasticity (Clem and Huganir, 2010), strengthening of PL-BLA synapses depended on stimulus associativity and was correlated with the presence of tone-evoked freezing (Fig. 5). Thus, while PL and BLA contribute to context fear that exists in both trained mice as well as unpaired controls (Goosens and Maren, 2001; Corcoran and Quirk, 2007), our results suggest that PL-BLA transmission plays a specific role in cued associations consistent with the tone responsiveness of BLA-projecting PL neurons (Courtin et al., 2014). However, these results raise the question of which $\mathrm{MPFC}$ and BLA circuits support context fear encoding. A possible substrate for these associations would be synaptic connections between these areas and the hippocampus, which is required for contextual but not auditory fear conditioning (Phillips and LeDoux, 1992).

Overall, our data point to a postsynaptic locus for expression of PL excitatory synaptic strengthening and a corresponding increase in excitation:inhibition balance in the basal amygdala. Specifically, fear conditioning increases the postsynaptic efficacy of glutamate transmission through changes in AMPAR conductance. We speculate that the small proportion of synapses affected by this enhancement might have precluded a shift in the distribution of sEPSC amplitudes in BLA neurons (Fig. 2). On the other hand, we failed to identify a mechanism for increased
sEPSC frequency in trained animals. This effect may be attributable to synapse formation or increased glutamate release at other afferent pathways, such as those traversing the external capsule (Tsvetkov et al., 2002), or within recurrent connections between BLA neurons.

Coincident with postsynaptic enhancement, we observed an increase in the contribution of CP-AMPARs at PL synapses. Previously, we found that CP-AMPARs undergo a GluA1 phosphorylation-dependent accumulation at thalamic synapses in the lateral amygdala after fear conditioning (Clem and Huganir, 2010), and are removed during retrieval-extinction, a protocol designed to exploit the adaptive function of reconsolidation. Compared with conventional extinction, retrieval-extinction is equally effective at reducing CS responses, but generates an augmented form of fear attenuation that is not subject to spontaneous recovery, renewal, or reinstatement (Monfils et al., 2009; Schiller et al., 2013). Because synaptic correlates of fear expression (present study) and extinction (Cho et al., 2013) may coexist at mPFC-BLA pathways, it would be valuable to determine whether persistent fear attenuation is associated with distinct changes in PL or IL transmission, and whether CP-AMPAR dynamics contribute to these effects.

In conclusion, our results indicate that synaptic correlates of auditory fear conditioning extend beyond sensory inputs to the BLA. In particular, the acquisition of CS responses correlates with selective strengthening of PL excitatory synapses in the basal nucleus. Given increased activation of dACC (Milad et al., 2009) and BLA in PTSD (Liberzon and Sripada, 2008), these data suggest a mechanism by which fear-related activity might be amplified within mPFC-BLA networks, contributing to persistent and uncontrollable emotional reactions. 


\section{References}

Britt JP, Benaliouad F, McDevitt RA, Stuber GD, Wise RA, Bonci A (2012) Synaptic and behavioral profile of multiple glutamatergic inputs to the nucleus accumbens. Neuron 76:790-803. CrossRef Medline

Burgos-Robles A, Vidal-Gonzalez I, Quirk GJ (2009) Sustained conditioned responses in prelimbic prefrontal neurons are correlated with fear expression and extinction failure. J Neurosci 29:8474-8482. CrossRef Medline

Cho JH, Deisseroth K, Bolshakov VY (2013) Synaptic encoding of fear extinction in mPFC-amygdala circuits. Neuron 80:1491-1507. CrossRef Medline

Clem RL, Barth A (2006) Pathway-specific trafficking of native AMPARs by in vivo experience. Neuron 49:663-670. CrossRef Medline

Clem RL, Huganir RL (2010) Calcium-permeable AMPA receptor dynamics mediate fear memory erasure. Science 330:1108-1112. CrossRef Medline

Clem RL, Huganir RL (2013) Norepinephrine enhances a discrete form of long-term depression during fear memory storage. J Neurosci 33:1182511832. CrossRef Medline

Corcoran KA, Quirk GJ (2007) Activity in prelimbic cortex is necessary for the expression of learned, but not innate, fears. J Neurosci 27:840-844. CrossRef

Courtin J, Chaudun F, Rozeske RR, Karalis N, Gonzalez-Campo C, Wurtz H, Abdi A, Baufreton J, Bienvenu TC, Herry C (2014) Prefrontal parvalbumin interneurons shape neuronal activity to drive fear expression. Nature 505:92-96. CrossRef Medline

Cruikshank SJ, Urabe H, Nurmikko AV, Connors BW (2010) Pathwayspecific feedforward circuits between thalamus and neocortex revealed by selective optical stimulation of axons. Neuron 65:230-245. CrossRef Medline

Frankland PW, Josselyn SA, Anagnostaras SG, Kogan JH, Takahashi E, Silva AJ (2004) Consolidation of CS and US representations in associative fear conditioning. Hippocampus 14:557-569. CrossRef Medline

Goosens KA, Maren S (2001) Contextual and auditory fear conditioning are mediated by the lateral, basal, and central amygdaloid nuclei in rats. Learn Mem 8:148-155. CrossRef Medline

Hong I, Kim J, Lee S, Ko HG, Nader K, Kaang BK, Tsien RW, Choi S (2013) AMPA receptor exchange underlies transient memory destabilization on retrieval. Proc Natl Acad Sci U S A 110:8218-8223. CrossRef Medline

Hübner C, Bosch D, Gall A, Lüthi A, Ehrlich I (2014) Ex vivo dissection of optogenetically activated mPFC and hippocampal inputs to neurons in the basolateral amygdala: implications for fear and emotional memory. Front Behav Neurosci 8:64. CrossRef Medline

Kauer JA, Malenka RC, Nicoll RA (1988) A persistent postsynaptic modification mediates long-term potentiation in the hippocampus. Neuron 1:911-917. CrossRef Medline

Lammel S, Ion DI, Roeper J, Malenka RC (2011) Projection-specific modulation of dopamine neuron synapses by aversive and rewarding stimuli. Neuron 70:855-862. CrossRef Medline

Liberzon I, Sripada CS (2008) The functional neuroanatomy of PTSD: a critical review. Prog Brain Res 167:151-169. CrossRef Medline

Likhtik E, Pelletier JG, Paz R, Paré D (2005) Prefrontal control of the amygdala. J Neurosci 25:7429-7437. CrossRef Medline

Lin HC, Tseng YC, Mao SC, Chen PS, Gean PW (2011) GABAA receptor endocytosis in the basolateral amygdala is critical to the reinstatement of fear memory measured by fear-potentiated startle. J Neurosci 31:88518861. CrossRef Medline

Little JP, Carter AG (2013) Synaptic mechanisms underlying strong reciprocal connectivity between the medial prefrontal cortex and basolateral amygdala. J Neurosci 33:15333-15342. CrossRef Medline

Marek R, Strobel C, Bredy TW, Sah P (2013) The amygdala and medial prefrontal cortex: partners in the fear circuit. J Physiol 591:2381-2391. Medline

Maren S, Phan KL, Liberzon I (2013) The contextual brain: implications for fear conditioning, extinction and psychopathology. Nat Rev Neurosci 14:417-428. CrossRef Medline

Mcdonald AJ, Mascagni F, Guo L (1996) Projections of the medial and lateral prefrontal cortices to the amygdala: a Phaseolus vulgaris leucoagglutinin study in the rat. Neuroscience 71:55-75. CrossRef Medline

McKernan MG, Shinnick-Gallagher P (1997) Fear conditioning induces a lasting potentiation of synaptic currents in vitro. Nature 390:607-611. CrossRef Medline
Milad MR, Quirk GJ (2002) Neurons in medial prefrontal cortex signal memory for fear extinction. Nature 420:70-74. CrossRef Medline

Milad MR, Quirk GJ, Pitman RK, Orr SP, Fischl B, Rauch SL (2007) A role for the human dorsal anterior cingulate cortex in fear expression. Biol Psychiatry 62:1191-1194. CrossRef Medline

Milad MR, Pitman RK, Ellis CB, Gold AL, Shin LM, Lasko NB, Zeidan MA, Handwerger K, Orr SP, Rauch SL (2009) Neurobiological basis of failure to recall extinction memory in posttraumatic stress disorder. Biol Psychiatry 66:1075-1082. CrossRef Medline

Monfils MH, Cowansage KK, Klann E, LeDoux JE (2009) Extinctionreconsolidation boundaries: key to persistent attenuation of fear memories. Science 324:951-955. CrossRef Medline

Morozov A, Sukato D, Ito W (2011) Selective suppression of plasticity in amygdala inputs from temporal association cortex by the external capsule. J Neurosci 31:339-345. CrossRef Medline

Muller D, Joly M, Lynch G (1988) Contributions of quisqualate and NMDA receptors to the induction and expression of LTP. Science 242:16941697. CrossRef Medline

Nabavi S, Fox R, Proulx CD, Lin JY, Tsien RY, Malinow R (2014) Engineering a memory with LTD and LTP. Nature 511:348-352. CrossRef Medline

Pape HC, Pare D (2010) Plastic synaptic networks of the amygdala for the acquisition, expression, and extinction of conditioned fear. Physiol Rev 90:419-463. CrossRef Medline

Pendyam S, Bravo-Rivera C, Burgos-Robles A, Sotres-Bayon F, Quirk GJ Nair SS (2013) Fear signaling in the prelimbic-amygdala circuit: a computational modeling and recording study. J Neurophysiol 110:844-861. CrossRef Medline

Phelps EA, Delgado MR, Nearing KI, LeDoux JE (2004) Extinction learning in humans: role of the amygdala and vmPFC. Neuron 43:897-905. CrossRef Medline

Phillips RG, LeDoux JE (1992) Differential contribution of amygdala and hippocampus to cued and contextual fear conditioning. Behav Neurosci 106:274-285. CrossRef Medline

Rogan MT, Stäubli UV, LeDoux JE (1997) Fear conditioning induces associative long-term potentiation in the amygdala. Nature 390:604-607. CrossRef Medline

Rosenkranz JA, Grace AA (2001) Dopamine attenuates prefrontal cortical suppression of sensory inputs to the basolateral amygdala of rats. J Neurosci 21:4090-4103. Medline

Rosenmund C, Clements JD, Westbrook GL (1993) Nonuniform probability of glutamate release at a hippocampal synapse. Science 262:754-757. CrossRef Medline

Schiller D, Kanen JW, LeDoux JE, Monfils MH, Phelps EA (2013) Extinction during reconsolidation of threat memory diminishes prefrontal cortex involvement. Proc Natl Acad Sci U S A 110:20040-20045. CrossRef Medline

Senn V, Wolff SB, Herry C, Grenier F, Ehrlich I, Gründemann J, Fadok JP, Müller C, Letzkus JJ, Lüthi A (2014) Long-range connectivity defines behavioral specificity of amygdala neurons. Neuron 81:428-437. CrossRef Medline

Sesack SR, Deutch AY, Roth RH, Bunney BS (1989) Topographical organization of the efferent projections of the medial prefrontal cortex in the rat: an anterograde tract-tracing study with Phaseolus vulgaris leucoagglutinin. J Comp Neurol 290:213-242. CrossRef Medline

Sierra-Mercado D, Padilla-Coreano N, Quirk GJ (2011) Dissociable roles of prelimbic and infralimbic cortices, ventral hippocampus, and basolateral amygdala in the expression and extinction of conditioned fear. Neuropsychopharmacology 36:529-538. CrossRef Medline

Tsvetkov E, Carlezon WA, Benes FM, Kandel ER, Bolshakov VY (2002) Fear conditioning occludes LTP-induced presynaptic enhancement of synaptic transmission in the cortical pathway to the lateral amygdala. Neuron 34:289-300. CrossRef Medline

Tye KM, Stuber GD, de Ridder B, Bonci A, Janak PH (2008) Rapid strengthening of thalamo-amygdala synapses mediates cue-reward learning. Nature 453:1253-1257. CrossRef Medline

Zhou Y, Won J, Karlsson MG, Zhou M, Rogerson T, Balaji J, Neve R, Poirazi P, Silva AJ (2009) CREB regulates excitability and the allocation of memory to subsets of neurons in the amygdala. Nat Neurosci 12:1438 1443. CrossRef Medline 